\title{
CORRESPONDENCE
}

\section{Block changes to Brazil's Forest Code}

Brazil's House of Representatives last month approved profound changes to the Forest Code, a series of laws to regulate the country's land use. The changes would jeopardize ecosystems and allow deforestation of about 20 million more hectares than the original Forest Code, according to estimates by Gerd Sparovek of the University of São Paulo (see go.nature.com/ n8lwfu). The Brazilian Senate must seize its last opportunity to block the changes.

The proposed changes would substantially increase carbon emissions. Assuming that half of the newly affected forest (10 million hectares) will be given over to agriculture and that the average carbon biomass in the Amazon, Atlantic Forest and Cerrado is 50 megagrams per hectare (L. F. Alves et al. Forest Ecol. Manage. 260, 679-691; 2010), emissions would amount to some 500 teragrams of carbon on top of the 100-300 Tg that arise annually from deforestation of the Amazon (J. P. H. B. Ometto et al. Oecologia 143, 483-500; 2005).

The government's efforts to decrease Amazon deforestation would be wasted, as would investments made in the ethanol industry for a cleaner environment. Brazil's commitment to the environment could lose credibility internationally, causing developed countries to raise import taxes on Brazilian agricultural products, making them less competitive.

Such serious consequences would offset any short-term gain by the Brazilian agricultural sectors that might result from changes to the Forest Code.

Luiz Antonio Martinelli Centre for Nuclear Energy in Agriculture, Piracicaba, São Paolo, Brazil.

martinelli@cena.usp.br

\section{WHO working to be fit for purpose}

As director-general of the World Health Organization (WHO), I disagree with Barry Bloom's suggestion (Nature 473, 143$145 ; 2011)$ that the international community no longer trusts the WHO.

In the first half of this year, after intense long-term negotiations, the WHO delivered three significant agreements for public health: on influenza virus and benefit sharing; on non-communicable diseases; and on accountability in women's and children's health. These agreements could never have been reached without international trust in the $\mathrm{WHO}$ and great diplomacy and flexibility from the participants. Last month's World Health Assembly followed up with a progress report (see go.nature. com/jbqjy1).

Global health is important for every country. I am working with colleagues and member states to strengthen the WHO. Last year, I began a consultation with the organization's six regions to make our systems more effective, efficient and transparent. I will continue to work to make the WHO fit for purpose in the twenty-first century.

Margaret Chan World Health Organization, Geneva, Switzerland.

feigc@who.int

\section{Population bomb: the UN responds}

Fred Pearce's view of the latest United Nations population projections misrepresents our results (Nature 473, 125; 2011).

The causes of the differences between the 2008 and the 2010 revisions are more complex and varied than he conveys.
The figures he cites to show that fertility estimates are lower than those made two years ago are the projected fertility figures for $2010-15$ in the 2010 revision. The most recent estimates refer to 2005-10 and show an increase in fertility with respect to the 2008 revision in 84 countries, a decrease in 56 countries, and no change in the other 57 countries considered. Estimated fertility for 2005-10 is higher in the 2010 revision for both developed and least-developed countries.

In the 2008 revision, projections stopped in 2050. The differences in fertility between the 2010 revision and the 2008 revision in 2045-50 are generally small: 110 countries have higher fertility and 87 have lower fertility in the 2010 revision. In about half of those countries, the differences arise partly from revised higher or lower estimates, respectively, for 2005-10 (for a peer-reviewed description of projection methodology, see L. Alkema et al. Demography; in the press).

Contrary to Pearce's suggestion, no country maintains a fertility of 2.1 children per woman between 2010 and 2100 in the medium variant of the 2010 revision. In that variant, projected fertility is lower than 2.1 by $2095-2100$ in 182 of the 197 countries. Furthermore, the populations of 118 countries $-55 \%$ of the world population - are projected to be declining by 2100 , indicating that their fertility levels are projected to stay well below 2.1 for several decades.

The medium variant of the 2010 revision produces a 2050 world population that is, as Pearce notes, 156 million higher than that projected in the 2008 revision. This $1.7 \%$ difference is comparable to that between earlier revisions produced during this decade.

Hania Zlotnik Population Division, United Nations, New York, USA.

zlotnik@un.org

\section{More at stake in} stem-cell patents

Austin Smith and others argue in favour of patenting technologies derived from human embryonic stem cells (Nature 472, 418; 2011), a case still pending with the European Court of Justice. But there is more at stake than European commercial interests.

In 1998, agreement was reached in Europe under Directive 98/44 not to recognize patents involving the use of human embryos for commercial purposes (R. Hipp and P. Liese Nature 474, 36; 2011).

The court must decide whether the use of these cells 'necessitates the prior destruction of human embryos or their use as base material', as the advocategeneral, Yves Bot, has argued (see go.nature.com/gsap8n). If so, such use would seem to fall beyond the scope of what is legally patentable.

Smith et al. warn that "European discoveries could be translated into applications elsewhere, at a potential cost to the European citizen." This begs the question of whether patents, which may also be held by non-European companies, may sometimes impede wider research cooperation (S. Rabin Nature Biotechnol. 23, 817-819; 2005).

In any case there will often be some commercial risk whenever Europe defends a more rigorous ethical standard than is defended elsewhere. This risk is not itself an argument against upholding the standard prescribed by law.

Without prejudice to the final judgment in this case, the resolution of patent law is and ought to be more than a question of European commercial interest. David Albert Jones ${ }^{\star}$ Anscombe Bioethics Centre, Oxford, UK. director@bioethics.org.uk ${ }^{*}$ On behalf of 25 co-signatories (see go.nature.com/2bkno7). 